\title{
Effects of Jinan-Heze Expressway on Flood Detention Function of Daotunwa Wetland in China on Remote Sensing Techniques
}

\author{
Jiemin Cheng ${ }^{1}$, Xiaofeng Wang ${ }^{1}$, Guanglu $\mathrm{Hu}^{2}$, Cuicui $\mathrm{Wu}^{1}$ \\ ${ }^{1}$ College of Population Resources and Environment, Shandong Normal University, 250014 Jinan China \\ ${ }^{2}$ School of Information Engineering, Shandong Youth University of Political Science, 250014 Jinan China
}

\begin{abstract}
The location map of Daotunwa Wetland and Jinan-Heze expressway was created based on 35 technology in order to study the relationship among wetland area, its flood storage capacity and the Jinan-Heze expressway construction. The results showed that Jinan-Heze expressway covered 0.11 $\mathbf{k m}^{2}$ of the Daotunwa wetland, thus it could be inferred that the wetland water volume would decrease $0.011 \times 109 \mathrm{~m}^{3}$. Although the expressway could introduce a loss to the wetland flood storage capacity, the effect of expressway on detention function of wetland is negligible. However, since the Jinan-Heze expressway divides the Daotunwa wetland into two parts (the west $26.5 \mathrm{~km}^{2}$, the east $0.75 \mathrm{~km}^{2}$ ), the effects of flood on expressway could be obvious, in cases that the flood was/is at the speed level of $7000 \mathrm{~m}^{3} / \mathrm{s}$ in the Shangliuze hydrologic station of Daqing river and enter the wetland from eastern side of Jinan-Heze expressway.
\end{abstract}

Keywords-expressway; wetland; flood detention.

\section{INTRODUCTION}

The expressway is the infrastructure for the social and economy development of the area[1]. Jinan-Heze expressway passes four cities and eight counties with a length of about $157 \mathrm{~km}$ It plays an important role in the economic development in the central and western regions of Shandong province in Eastern China. Daotunwa wetland, located $3 \mathrm{~km}$ away from the west of Dongping County, north bank of Daqing River, is the retention areas of Dongping Lake. Jinan-Heze expressway passes through the east part of the Daotunwa wetland and divids the wetland into two parts. As a seasonal wetland, Daotunwa wetland area, ecological structure and flood control functions changes largely with seasons. The construction of Jinan-Heze expressway will occupy part of the wetland area, which will produce certain negative effects on its flood detention function [2].

The flood regulation storage function is one of the most important wetland values. Those wetlands connected with rivers generally have the flood storage function, including reservoir flood, slowing the flood flow velocity, reducing flood peak and prolonging the flow time etc. The ability of wetland flood storage function is attributed to the wetland's characteristics, such as size, position, and wetland types [4]. The greater the wetland area is, the greater the ability of slow flow.
The map of Daotunwa wetland and Jinan-Heze expressway was obtained by processing the wetland remote sensing image using $3 \mathrm{~S}$ technology to study the changes of the wetland area and its flood storage capacity with water level variation. The purpose of this research is to investigate the effects of Jinan-Heze expressway on the wetland's detention function.

\section{STUDY SITES}

Daotunwa wetland is located $3 \mathrm{~km}$ away from the west of Dongping County, north bank of Daqing River ( $35^{\circ} 55^{\prime} 00^{\prime \prime}$ $35^{\circ} 57^{\prime} 30^{\prime \prime} \mathrm{N}$; $116^{\circ} 18^{\prime} 54^{\prime \prime}-116^{\circ} 20^{\prime} 30^{\prime \prime} \mathrm{E}$ ). The area of total drainage basin of the Daotunwa wetland is approximately $24.8 \mathrm{~km}^{2}$, including perennial water area of $8 \mathrm{~km}^{2}$. Daotunwa wetland is the catchment region of the river and the slope water in the north of Dongping county, with a catchment area about $272 \mathrm{~km}^{2}$. Daotunwa wetland is in the north temperate zone, belonging to a temperate continental monsoon climate, with four season characteristics. Its annual average temperature is $13.4{ }^{\circ} \mathrm{C}$, and the average precipitation $640 \mathrm{~mm}$. Daotunwa wetland is part of the detention areas of low-lying and flat. Soil in the area is loamy sand.

The types of land in Daotunwa wetland consists water body, agricultural land, forest land and barren hills (mainly for the bare rock). The wetland contains Xi Xin Zhuang, Meng, Bai Hu, He Gou, Bian and Daotun villages, and the total population is 14542 , and the cultivated area is $12.6 \mathrm{~km}^{2}$.

The atmospheric environment and the acoustic environment quality are good in Daotunwa wetland, even though the water quality of the main catchment River Baijihe is poor, and all water quality indexes are above the grade $\mathrm{V}$ of the Environmental Quality Standards for Surface Water (GB3838-2002). The water quality indexes of Daqing River are even better with grade II-III of the Environmental Quality Standards for Surface Water. The biological resources are abundant: there are many rare plants and animals; 190 bird species belonging to 17 orders, 38 families; 40 species aquatic plants; 471 species fruit woody plants belonging to 71 families, 488 species traditional Chinese medicinal plants belonging to 110 families. 


\section{DATA ACQUISITION AND PROCESSING METHOD}

The relationship between the Daotunwa wetland area and the location of Jinan-Heze expressway was determined by $3 \mathrm{~S}$ technology. Based on the analysis of the wetland area, combined with interpretation process and subsidiary positioning of GPS, all the different color patches were interpreted and the location of Jinan-Heze expressway and Daotunwa wetland was drawn. The basic process was shown in Fig.1.

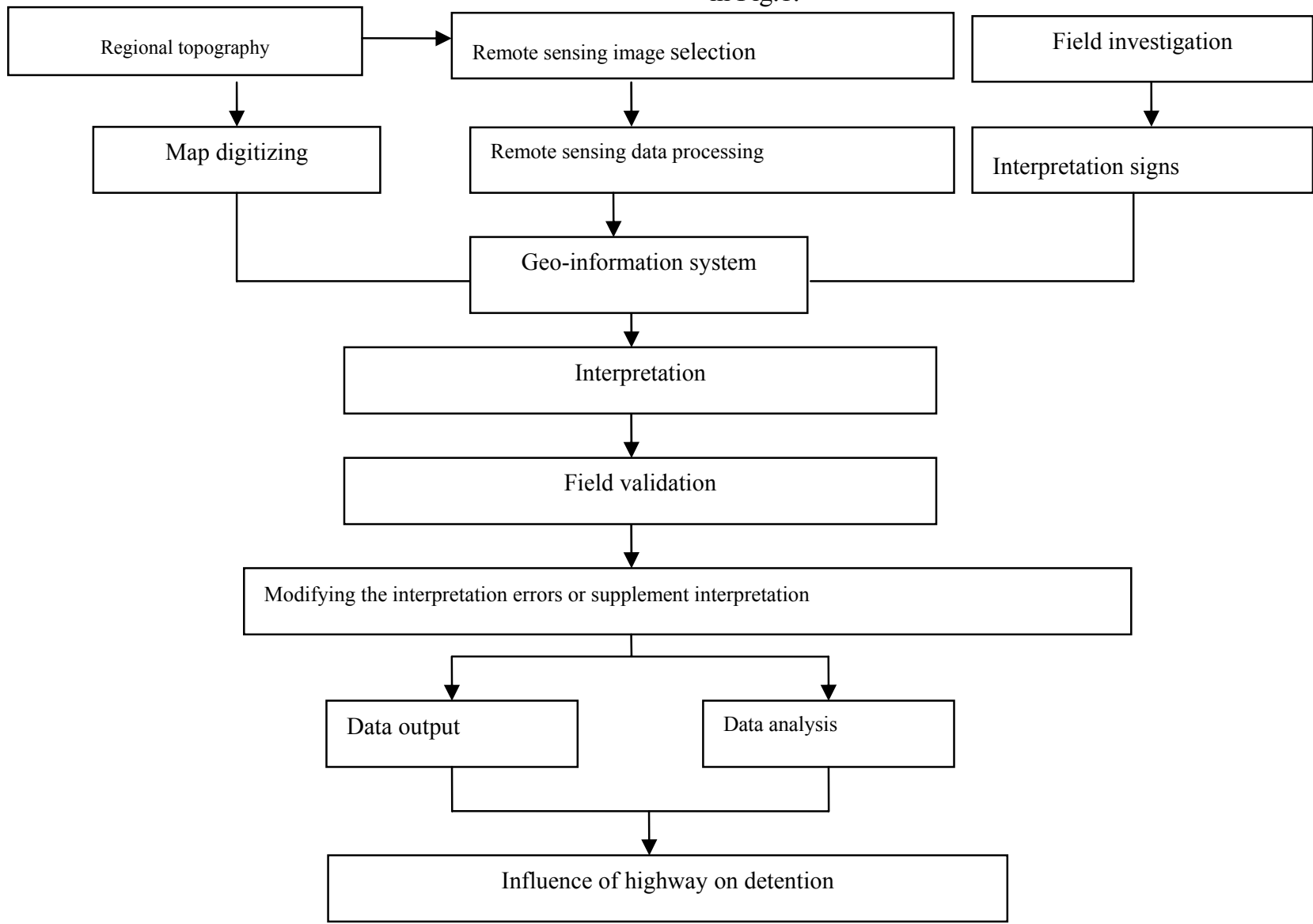

Figure 1. Flow chart of wetland remote sensing monitoring

\section{A. Selection of Remote sensing data source}

China-Brazil Earth Resources Satellite CBERS remote sensing image was selected as data sources after the Jinan-Heze expressway was constructed in Dec, 2009. The pixel spatial resolution was $19.5 \times 19.5 \mathrm{~m}$.

\section{B. Pre-processing of remote sensing image}

ERDAS IMAGINE Image 8.5 developed by American Lexica Company was selected to pre-process the remote sensing image, such as radiometric correction, geometric correction, color enhancement and false color composite. We then digitized topographic map image using ARCINFO, finally to get the thematic image map (Fig.2) [3].

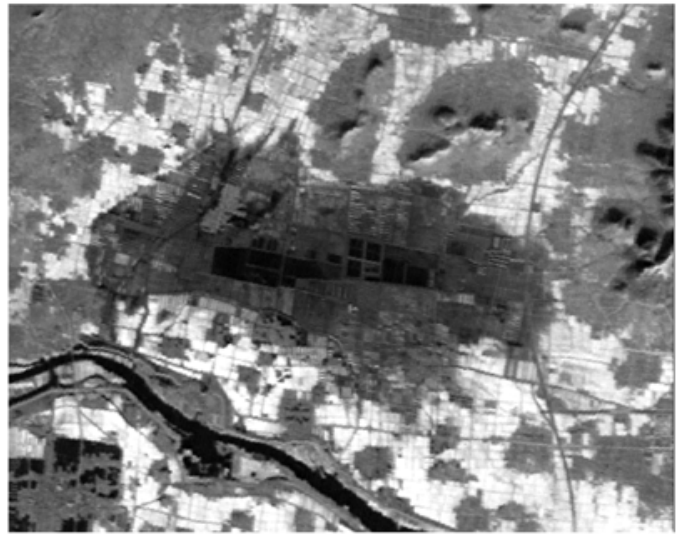

Figure 2. Remote sensing image after pretreatment

The process was as following:

i) Selection of the control points: in 1:50000 topographic map, several obvious and uniform distribution points were 
selected as the geometric control points, and kept in the record.

ii) Albers projection and polynomial methods of geometric correction were applied to geometric rectification and re-sampling.

iii) Combing the characteristics of wetland and Jinan-Heze expressway, the practical exploration and the image features of satellite, the imaging features of Jinan-Heze expressway in wetland image were obtained. The color, luster, texture, geometry images were recorded, and the judgment survey marks were built.

iv) Color composite, image enhancement, multi band combination were added to the wetland and the expressway, and then the thematic information was extracted.

Through the above steps, wetland area and expressway data were collected to provide the basic data for analysis and prediction for the future. Remote sensing image was showed in Remote sensing image after pretreatment.

\section{Analysis and interpretation process}

The treated remote sensing images and other data were input into geographic information system, and the wetland types were interpreted. After pretreatment remote sensing image and according to the topographic map of the study area, ArcInfo software was used to interpret the remote sensing image, draw wetland and expressway profile, and the cartography was created using ArcView software.

\section{RESUlTS AND DISCUSSION}

\section{A. Regulation and Storage function of Daotunwa wetland}

Water storage capacity of Daotunwa wetland under different water level and flooded area was shown in Fig.3 and Fig.4.

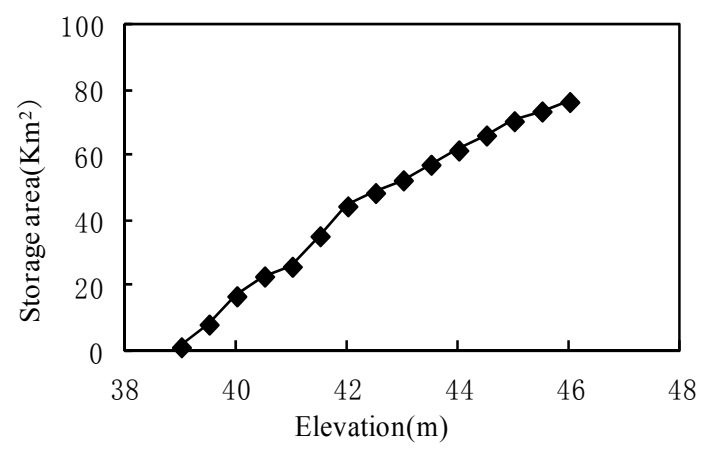

Figure 3. Relation between Daotunwa water level and storage area

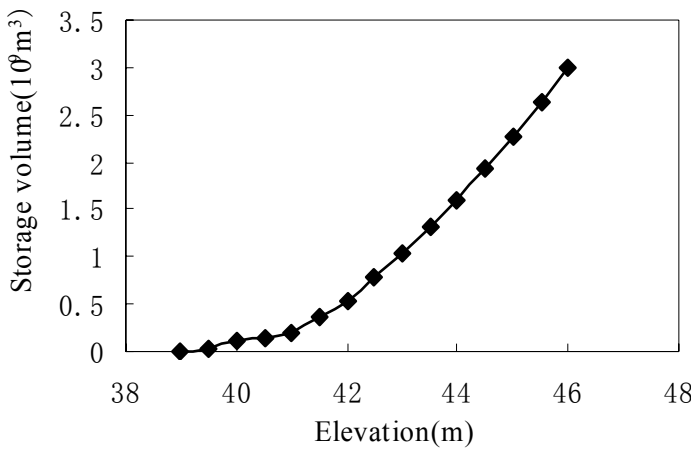

Figure 4. Relation between Daotunwa water level and storage volume

As shown in above figures, the water area and storage capacity increased linearly with the increase of water depth. When the elevation was between $39 \mathrm{~m}-41 \mathrm{~m}$, wetland water area was small. While the elevation was above $41 \mathrm{~m}$, the wetland storage capacity increased rapidly with the rapid growth of the wetland water area. When the elevation reached the designed highest water level $46 \mathrm{~m}$ in flood detention, the storage capacity reached a maximum of 300 million $\mathrm{m}^{3}$.

\section{B. Effects of Jinan-Heze expressway on the wetland area}

The fig. 5 shows the electronic map made using Arcview software. As shown in Figure, .Daotunwa wetland was divided into two parts. The west part is $26.5 \mathrm{~km}^{2}$, the east part is $0.75 \mathrm{~km}^{2}$, and the wetland occupied by Jinan-Heze expressway covered an area of about $0.11 \mathrm{~km}^{2}$. Considering that the average elevation of Daotunwa wetland was $39 \mathrm{~m}$, and the expressway embankment was $5 \mathrm{~m}$, it can be inferred that the wetland water volume is reduced by $0.011 \times 109 \mathrm{~m}^{3}$ because of the occupation by Jinan-Heze expressway.

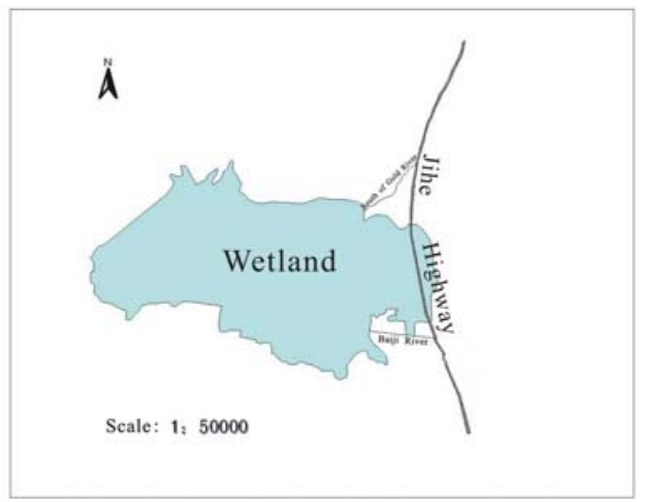

Figure 5. Distribution of Daotunwa wetland and Jinan-Heze expressway

\section{Effects of different flood discharging ways on the Jinan-Heze expressway}

If there is a flood at the speed of $7000 \mathrm{~m}^{3} / \mathrm{s}$ in the Shangliuze hydrologic station of Daqing river, the South embankment would be under threat and would have to burst in the North embankment of Daqing river located in the 
south of Makou village, then the flood will enter the wetland from eastern side of Jinan-Heze expressway. Because the wetland area in the east of the expressway is relatively small, the flood will flow quickly and the flood peak increased rapidly, and the expressway would likely be submerged. When Dongping Lake released flood waters to Daotunwa wetland, owing to the wide wetland area on the west side of the expressway, the flood will reach the expressway at a lower speed, the expressway could not be drowned easily/reducing the potential damage to the expressway. In summary, although expressway could cause a loss to the wetland flood storage capacity, but the effect of expressway on detention function of wetland is limited.

\section{CONCLUSIONS}

Jinan-Heze expressway construction had positive effect to promote the regional social economic development. Jinan-Heze expressway covers $0.11 \mathrm{~km}^{2}$ of the Daotunwa wetland, so it could be inferred that the wetland water volume would decrease $0.011 \times 109 \mathrm{~m}^{3}$. Although expressway could cause a loss to the wetland flood storage capacity, the effect of expressway on detention function of wetland was little. Because Jinan-Heze expressway divided the Daotunwa wetland into two parts ( the west $26.5 \mathrm{~km}^{2}$, the east $0.75 \mathrm{~km}^{2}$ ), the effects of flood on expressway should not be under estimated if the flood reaches the speed level of $7000 \mathrm{~m}^{3} / \mathrm{s}$ in the Shangliuze hydrologic station of Daqing river and enter the wetland from eastern side of Jinan-Heze expressway.

\section{REFERENCES}

[1] Fan Zhenyu, Xiao Chunyang: Analysis of Expressway Construction Effects on National Socio-economic Development of China. Journal of Highway and Transportation Research and Development (2006) 23(5):155-158

[2] Liu Su, Zhang Chonglu, Sun Guoqing, Xu Zhuokui, Zhao Kejin: Several questions of assessment of influence by highway on dongting lake ecotope. Journal of Railway Science and Engineering (2006) 3(2):85-89.

[3] Lv Xianguo, Liu Hongyu: Protection and Management of Wetland Ecological System, Chemical Industry Press, (2004) Beijing

[4] Pan Hui, Luo Cailian, Tan Fanglin: Application of 3S Technology to Wetland Researches, Wetland Science (2006) 4(1):75-79 